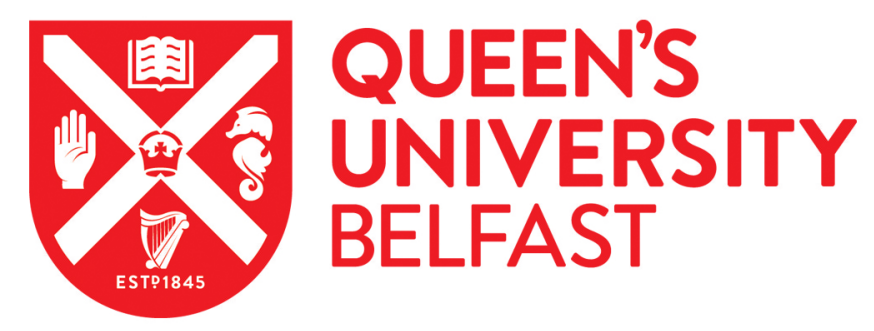

\title{
Improving sexual healthcare delivery for men in prison: A nurse-led initiative
}

Kelly, C., Templeton, M., Allen, K., \& Lohan, M. (2020). Improving sexual healthcare delivery for men in prison: A nurse-led initiative. Journal of Clinical Nursing, 1-8. https://doi.org/10.1111/jocn.15237

Published in:

Journal of Clinical Nursing

Document Version:

Peer reviewed version

Queen's University Belfast - Research Portal:

Link to publication record in Queen's University Belfast Research Portal

Publisher rights

Copyright 2020 Wiley. This work is made available online in accordance with the publisher's policies. Please refer to any applicable terms of use of the publisher.

\section{General rights}

Copyright for the publications made accessible via the Queen's University Belfast Research Portal is retained by the author(s) and / or other copyright owners and it is a condition of accessing these publications that users recognise and abide by the legal requirements associated with these rights.

Take down policy

The Research Portal is Queen's institutional repository that provides access to Queen's research output. Every effort has been made to ensure that content in the Research Portal does not infringe any person's rights, or applicable UK laws. If you discover content in the Research Portal that you believe breaches copyright or violates any law, please contact openaccess@qub.ac.uk. 


\section{Abstract}

\section{Aims and objectives:}

The study aim was to develop and evaluate a nurse-led sexual health service and health promotion intervention for men in prison.

\section{Background:}

Men in prison are particularly marginalised members of our society, negatively impacting on their ability to making healthy choices. In relation to sexual health, prison provides an opportunity for curative and preventive care, for an otherwise often hard to reach priority population.

\section{Design}

Practice development, audit and evaluation.

\section{Methods}

Employing a practice development and participatory methodology, we empowered prison nursing staff to provide robust asymptomatic testing for sexually transmitted infections, including the management of chlamydia, with appropriate treatment and partner notification. Collaboratively with young men and nursing staff, a short animation video to promote the service was developed.

A case note audit of 172 patients seen in the service during the 6 month period $1^{\text {st }}$ July 2018 - 31 December 2018 was undertaken.

The Standards for Quality Improvement Reporting Excellence (SQUIRE) checklist was followed.

\section{Results}

National outcomes measures were exceeded for some clinical outcomes. During the 6 month period, there were 12 positive chlamydia ( $7 \%$ positivity rate) and 3 gonorrhoea positive results. In addition, 2 new cases of syphilis were detected and a further 2 cases of known HIV were highlighted. There were 7 cases of Hepatitis $C$ ( 3 previously diagnosed) and 3 cases of Hepatitis B.

A short animation Dick Loves Doot was developed.

\section{Conclusion}

Successful partnerships between sexual health and prison healthcare services, in partnership with service users, can achieve well-co-ordinated services and health promotion interventions.

\section{Relevance to clinical practice}


This nurse led model of care increased detection and early treatment of asymptomatic STIs among men in prison, impacting positively the men, their partner (s) and the public health of the society to which they return.

\section{What does this paper contribute to the wider global clinical community?}

- Outlines a new model of nurse led sexual health service for men in prison.

- Details a robust clinical governance framework that meets standards for clinical excellence in sexual health care.

- Involves young men in prison in the co-production of an innovation sexual health promotion intervention. 


\section{Improving sexual healthcare delivery for men in Prison: A nurse led initiative}

Kelly, C., Templeton, M., Allen, K. and Lohan, M.

\section{INTRODUCTION}

Internationally, human rights standards stress that conditions of detention and punishment must not be prejudicial to health, and that, people living in prison should receive, at least, an equitable standard of care as the wider community (WHO, 2014). Addressing these needs requires that service development is driven by a patient centred vision, clearly defining the 'prisoner as patient'. Hence, in the United Kingdom, presently prison health care is managed by the National Health Service (NHS), within a primary care model, with an emphasis on increasing the roles of nurses in care provision.

\section{BACKGROUND}

Globally, the World Health Organisation (WHO) recognises two compelling reasons for providing health and sexual healthcare in prisons. First is the importance to public health, in that most prisoners will return to the community, carrying back with them untreated infections. Secondly they refer to society's responsibility to social justice and reducing health inequalities, as the majority of prisoners come from the poorest parts of society, with deficiencies in education and employment experience (WHO, 2014).

Men in prison are particularly excluded and marginalised members of our society (Farrington et al., 2016). Social deprivations, loss of freedom, negative stereotyping, and the cultural context of masculinity within their communities, all negatively impact 
on their ability to make healthy choices (Kupers, 2017). Consequently, the sexual behaviour of imprisoned men is more risky before entering prison, with this population tending to have more lifetime partners, engaging in riskier behaviour, such as injecting drug use or commercial sex activity, poor use of condoms and higher rates of STIs, including HIV and Hepatitis (see Condon et al., 2007 for review). Infection with blood borne viruses (BBVs) is higher in the prison population, largely due to higher levels of injecting drug use (Rumble et al, 2015). Added to that, high levels of poor mental health, alcohol and substance misuse, high risk sex within prison without access to condoms, will all impact on a prisoner's sexual health (Harris et al., 2006).

Typically there is a marked disparity of sexual health related services provided in male and female institutions, with males receiving less (Matthews et al., 2001). Whilst men characteristically make little use of primary healthcare services outside of prison, they make extensive use of services during imprisonment. For example, Marshall et al (2001) found that men, in UK prisons, consult doctors three times more and other health care professionals (mostly nurses) up to 80 times more than men in the community. In relation to sexual health, prison provides an opportunity for curative and preventive health care, for an otherwise often hard to reach, priority population, impacting positively on the individual, their partner (s) and the public health of the society to which they return. (WHO, 2014).

Previous surveys of sexual health services in UK prisons have shown that, prisons that had sexual healthcare services, typically employed staff from community Genitourinary medicine (GUM) clinics, which resulted in variable accessibility and frequency of clinics. In only $8.8 \%$ [5/44] of the prisons surveyed were the services delivered by nurse led services (Tang et al., 2010; Sherrard et al., 2007). However, in their qualitative study of prisoners' views about health services in prisons, Condon et al 
(2006) found that many of their participants took advantage of health promotion services and appreciated services offered by nurses.

Outside of the prison setting, across the UK and further afield, nurses have been taking on increased roles in sexual health care. Furthermore, developments in highly sensitive and specific tests, which do not require intimate examination, have created opportunities to further develop the role of nurses in providing services in locations (primary care, family planning, prison healthcare) outside the traditional setting of a genitourinary medicine clinic (GUM) (Auerbach et al., 2013).

Historically the prison system in Northern Ireland (NI) has been intimately connected with our particular experiences of the conflict which evolved from our divided society - the so-called Troubles. However, in moving towards a post-conflict society, it has been argued that for a prison system to be safe, humane and effective there is a need to move away from focussing on containment to instead focussing on increasing prisoners' social and human capital by providing opportunities for personal development and change (Ministry of Justice, 2016). Northern Ireland has three main correctional institutions. Responsibility for prison health care transferred from the Northern Ireland Prison Service (NIPS) to the Health and Social Care Board of Northern Ireland with a service agreement to provide services by the South Eastern Health \& Social Care Trust (SET) in 2008, with transfer of staff contracts completed in 2012. As elsewhere, prison healthcare is now increasingly primary care led with an emphasis on the expansion of roles and responsibilities of nurses (Rowniak \& Selix, 2015). However, prior to the commencement of this project there was no nurse involvement in sexual health services and no health promotion focus for these patients or the wider prison population (Butler, 2016). The sexual health service in NI prisons 
was a Consultant led in-reach service, primarily for symptomatic patients and with variable waiting times.

This paper, reports on one strand of a Burdett Trust for Nursing funded practice development project, which had two strands. In the first strand, we sought to empower nurses working within the prison to develop their knowledge and skills to provide robust Level 1 asymptomatic testing for sexually transmitted infections, including the management of chlamydia positive results with appropriate treatment and partner notification. In doing so, we sought to build on the successful evaluation of a new model of Level 1 sexual health care in primary care (Kelly et al., 2014), by introducing a similar nurse led service within prison healthcare. In the second strand, we worked with a smaller core of 8 nurses to develop their facilitation skills to provide health promotional activities with young men in prison. Collaboratively with young men, nursing staff and the research team, we developed a short animation video and posters to promote the service and a positive approach to sexual health check-ups (Templeton et al, 2019). The animation is freely available on Queen's University Belfast, School of Nursing and Midwifery YouTube channel (www.youtube.com/watch?v=eXAWctsAKys). Ethical approval was awarded by the Office for Research Ethics Committees Northern Ireland (reference: 17/NI/0082).

The aim of the paper is to report the development and evaluation of the nurse-led prison Level 1 sexual health service. The impetus for the project was the desire of the lead nurses from both sexual health and prison healthcare to work collaboratively to improve the sexual healthcare delivery to this hard to reach population, with a particular nursing orientation to practice. 
The structure of the paper is as follows. First, we describe the service development intervention which had three main components

- Delivery of a competency orientated training programme (level 1) for nursing staff within Prison Healthcare to provide comprehensive asymptomatic STI testing to heterosexual patients within the Northern Ireland Prison Service (NIPS).

- Development of a robust clinical governance framework for this nurse led initiative

- Patient-led health promotion to raise awareness of new service

Second, we report our methods of evaluation. Third, we report our results on clinical outcomes assessed against the UK standards for clinical excellence in sexual health care, and describe the broader acceptability of this new intervention.

Finally, we situate the results in terms of the changing landscape of prison healthcare and especially innovations in respecting the rights of people in prison/ patients to receive sexual health services to enhance their sexual health and wellbeing when in the prison environment. The Standards for Quality Improvement Reporting Excellence (SQUIRE) guidelines for reporting new knowledge about how to improve healthcare were followed.

\section{DESIGN AND METHODS}

\section{Project description}

This project involved a collaborative approach to practice development between the School of Nursing and Midwifery at Queen's University Belfast and the specialist sexual health and prison healthcare services of the South Eastern Health and Social 
Care Trust. The first expected outcome was that the nurses would be competent in undertaking a sexual health assessment and asymptomatic testing for chlamydia (CT), gonorrhoea (GC), syphilis, Hepatitis B\&C and HIV for heterosexual patients. . As recommended by the British Association of Sexual Health \& HIV (BASHH), men who have sex with men (MSM) should continue to be seen by a specialist sexual health service, given their unique care needs in relation to testing, vaccinations and discussion regarding pre exposure prophylaxis (PreP).

Training requirements included completion of nine core e-learning modules [http://www.e-Ifh.orq.uk/projects/hiv-sti/reqister.htmll and attendance at a formal one day training event. As this was expected to involve up to 55 nurses we had planned to repeat it 5 times throughout the year to facilitate groups of 10 being trained at any one time. The proposed care pathway was the emphasis of the training, with a particular focus on role playing exercises to enhance sexual history taking skills, understanding incubation periods for tests and managing positive results and partner notification. While information on post exposure prophylaxis (PEPSE) and vaccinations was given, the expectation was that this would require onward referral to medical staff. The nurses were also encouraged to attend an optional clinical session at the GUM clinic.

Nursing staff were supported by a patient group direction (PGD) and support from GP colleagues to instigate treatment and partner notification for positive CT results. While the primary focus of this project was improving the sexual health of men in prison, female prisoners also benefited and could request a check-up with the nurse also.

\section{Clinical governance}


To develop a robust clinical governance framework for this nurse led initiative, laboratory reporting systems were put in place to simultaneously inform the specialist Sexual Health Nurse Advisor of all positive results, ensuring a failsafe process for the appropriate management of positive results. A Consultant Nurse in sexual health and a sexual health nurse advisor are also available via a dedicated nurse helpline to provide support and advice for the appropriate management of all positive results received by the prison healthcare team. A system was put in place to refer patients, found to be positive for GC, Syphilis, Hepatitis or HIV, directly to the GUM Consultant. Given that the Consultant's planned clinics are held on a monthly basis, an email alert to the Consultant highlights positive results which may require earlier action.

\section{Patient- led health promotion to raise awareness of the service}

After an initial 30 nursing staff had completed the eLearning modules and formal training, a smaller core of 8 nurses attended a 3 day bespoke training programme in sexual health promotion (See Templeton et al., 2019). Further, employing a rights based participatory approach, a group of 6 young detained men , nursing staff, a media company and the research team worked collaboratively to create an innovative sexual health promotion intervention and promotional materials to promote the sexual health check -up service (see Templeton et al, 2019 for evaluation of this strand of the project).

The animation 'Dick Luvs Doot', co-created with the young men, is played on a TV monitor within prison health care. Nursing staff advertise the service within their prison by word of mouth (a sexual health check-up is offered and booked on committal), and the posters and leaflets, co-created with the young men are left at strategic points within their respective prisons, e.g., gym, canteen, recreational areas etc. Men can 
self-refer at any time during their time in custody. A poster and leaflets are also displayed in the family visits area to provide information for partners about the community sexual health nurse helpline should they need to use this service.

\section{Case Note Audit}

The research setting was 2 prison sites during the 6 month period $1^{\text {st }}$ July 2018 December 31, 2018. Data sources included activity recorded by the prison's Egton Medical Information System (EMIS), laboratory reports and databases completed by the prison health care nurse (all patients seen) and specialist sexual health adviser (positive cases only).The clinical records of patients attending the service during the 6 month period, were audited by CK for competence of care according to BASHH guidelines on sexual history taking and management of uncomplicated chlamydia. An audit proforma listed 8 key variables on documentation of sexual history (Table 1) and 3 key performance indicators (Table 2) on the management of chlamydia positive results.

Data was entered into a spreadsheet and analysed using an Excel dashboard to measure the key performance indicators. A total of 171 patient charts were reviewed, the majority $(n=146)$ were seen in a site housing approximately 870 adult male long term sentenced and remand prisoners (Site 1) and 25 were seen in a unit home to approximately 120 young male offenders and 70 female prisoners (site 2 ). A further 5 female patients seen in Site 2 during the period were excluded.

In addition, we conducted a brief open ended questionnaire, with 30 nurses before and after the Level 1 training day, and 8 nurses who attended the 3 day health promotion training, to gain an understanding of any learning gained. 


\section{RESULTS}

Each site has opted for different approaches, mainly based on the stability of their prison population and in managing staff workload. Site 2 provides a bimonthly service, led by a dedicated nurse (JM), who has the capacity to see 8- 10 patients in her clinic . Since July 2018, a weekly nurse led clinic has been provided by KA in Site 1, the busiest establishment, with a high turnover of remand prisoners.

\section{Patient age}

The majority were aged less than 30 years (65\%), with a further $35 \%$ aged over 31 years. (Figure 1)

\section{Key Performance Indicators (KPI)}

KPI: $97 \%$ of people accessing services with needs relating to STIs should have a relevant sexual history documented

The case note audit identified that $96 \%$ of patients had a sexual history documented across the 7 key variables. However, there were valid reasons as to why the other $4 \%$ did not have a sexual history completed, including symptoms that warranted direct referral to the GUM consultant, and attendance for follow up Hepatitis B 
vaccinations. Direct onward referral tended to be cases of genital warts. A comprehensive sexual history proforma was completed on all $96 \%$ of patients. (Figure 2)

KPI: $85 \%$ of patients with needs relating to STIs should be offered screening for chlamydia, gonorrhoea, syphilis and HIV at first attendance.

Given the higher risk of Hepatitis B and C within the patient population, all six tests were offered to $96 \%$ of patients attending, with a $94 \%$ uptake. On occasions were the men were unable to provide a urine sample or that they had recently passed urine this was added to the 'house nurse' workbook for the next day and followed up by KA.

KPI: All people having STI tests should have their results (both positive and negative).

The audit identified that how patients were to receive their results was documented in $92 \%$ cases. Within Site 2 , a smaller facility, the nurse provided the young men with their results face to face. Within Site 1 the nurse documented if the men were happy to receive a letter via the internal mail system regarding negative results. Given the higher turnover in this site, the nurse also recorded an external contact phone or address that was only to be used to inform of a positive result in cases were the men had been released prior to results becoming available. 


\section{Positive Results}

During the 6 month period of 1 July to December 31, 2018, there were in total 12 positive chlamydia results ( $7 \%$ positivity rate) and 3 gonorrhoea positive results. In addition, 2 new cases of syphilis were detected and a further 2 cases of known HIV were highlighted. There were 7 cases of Hepatitis C (3 previously diagnosed) and 3 new cases of Hepatitis B. While the chlamydia positive cases were managed by the nurse, all other positive cases were seen by the GUM consultant and referred to Hepatology.

Fifty percent $(n=6)$ of chlamydia cases were treated less than 2 working days from result received. A further $25 \%(n=3)$ were treated less than 4 working days from result and 2 cases took up to 9 working days to receive treatment. One patient did not receive treatment before being deported back to his home in Romania. Partner notification discussion was documented in 9/10 consultations (90\%) and all patients $(100 \%)$ had all 5 tests (CT/GC/HIV/Hep/Syp) completed.

\section{Nurse Evaluation}

The nurses' main motivations for attending the course were because they thought that the service should be available in prisons and they wanted to develop clinical skills and professional knowledge in sexual health nursing practice. The outcomes they hoped to achieve were to demonstrate knowledge and understanding of sexual health and current strategic priorities, be aware of factors that can potentially impact on 
sexual health and wellbeing, to interpret patients' information to identify risk levels, and to demonstrate clinical competence in assessing planning and managing sexual health care for patients.

- Manage an STI service within prison. Manage partner notification

- Able to assess and discuss sexual health with greater knowledge.

- Engage positively with clients.

- I am now more confident in discussing sexual health with patients.

For the vast majority, the course did not disappoint and their confidence levels about discussing and exploring sexual health issues and taking a sexual history with patients increased after the training. Most commented that they liked the interactive nature of the day and felt the facilitators were very knowledgeable and passionate about sexual health. They were eager to change their practice as a result of the training day and were keen to implement the service and engage with their patients about sexual health issues. Overall, the training received very positive evaluations. The main suggestion for improvements to the training focussed on access to and difficulty of the eLearning modules. On the back of this feedback the team will recommend for future groups that the eLearning modules are taken after the training day as opposed to before.

Evaluation of the 3 day course was equally positive and increased the nurses' confidence and motivation to deliver health promotion in group settings with their patients.

- Thank you very much for a very enjoyable and informative 3 days. 
- The course was delivered by a great team who made it very interesting and funny at times. A lot was learned and I am glad that I got the chance to participate in this.

- All the facilitators were very knowledgeable and approachable, very dedicated to the subject and made an enjoyable course

- Absolutely brilliant 3 days. All facilitators were fantastic. Love this area sexual health. Thank you all.

- I have had a complete U-turn on previous view that 1-to-1 sexual health education was better than group work. Now a convert to the idea of group work!

\section{DISCUSSION}

Healthcare in prisons across the UK is provided as a mainstream NHS service. Strategic priorities, including sexual health, have been set out within documents such as 'Improving Health, Supporting Justice' (2009), with the role of primary care as provider specified in 'Developing and Modernising Primary Care in Prisons' - 'the majority of prisoners' health needs will be met by primary care as they would in the wider community' (Department of Health / HM Prison Service 2002, p.5.). The focus is clearly that 'prisoners as patients' have the right to healthcare, appropriate to their needs and delivered to the same standard as the rest of the population. In addition, prison has been identified as an opportunity for preventive health care for an otherwise hard to reach group. Included in this is access to sexual health services. However, making this a reality is slow, with most prisons in the UK adopting an in- reach GUM service approach with variable accessibly and frequency of clinics. 
This project represented a novel and comprehensive intervention, involving prison nursing staff in a strong collaborative partnership with the specialist sexual health service, and, a further partnership with young men in prison in the co-design of a health promotion intervention to promote the service. This partnership, has facilitated a robust clinical governance framework for the service, in terms of training, active engagement, and opportunities to work alongside GUM staff. Importantly, a failsafe laboratory reporting system of positive results to the Sexual Health Nurse Advisor ensures appropriate management of positive results. An unanticipated positive outcome from this arrangement is that the in-reach GUM Consultant (who attends monthly) is made aware of positive results of gonorrhoea, HIV, Syphilis and Hepatitis, in a timelier manner, facilitating an appropriate response.

Improving access to a sexual health service within prisons is an important challenge, but also a significant opportunity. Previous research has highlighted inconsistency and deficiency in sexual health services available to prisoners in the UK (Tang et al, 2010) and identified challenges including lack of space and time, high nonattendance rate, due to rapid prison turnover, court attendances and legal visits (Sherrard et al., 2007). During the six month period that we evaluated there was one morning, when all ten patients booked, failed to attend for 'prison operational reasons'. Our evaluation also highlighted other challenges, in particular to the prison context, including partner notification and difficulty in providing treatment following release and / or deportation. However, because the nurse recorded permission to use an external contact number on release for positive results, she was able to follow up on a new diagnosis of Hepatitis B and inform the patient's GP, with his consent. Partner notification (PN), the corner stone of STI management, presented challenges for the prison healthcare nurses, particular to the context in which they 
work. While we had developed contact slips for use in primary care in the community, these were unusable by the prison population due to restrictions in handing anything over during prison visits. A requirement of the care pathway was to ensure follow up was possible with results (particularly for remand prisons) and that PN was discussed with anyone receiving a positive result. The men were encouraged to inform previous partners and give them the nurse advice telephone helpline (NAL) number so that attendance at a specialist service in the community could be arranged. In addition, posters advertising the NAL were displayed in the visitors' room in each site. The research we report here as well as previous research (Templeton et al, 2019) suggests the importance of including users in design and development of interventions and to especially address gendered barriers to men's involvement in sexual health.

National outcome standards were measured for some clinical outcomes showing that $90 \%$ of Chlamydia (CT) positive patients received treatment within 14 days, $94 \%$ received an HIV test and partner notification was documented as discussed in $90 \%$ of CT positive patients. The variance related to one patient who was deported prior to his result being available. The findings clearly show that robust arrangements are in place for training and providing ongoing support for the nurses, clinical governance and performance outcome measures, treatment and partner notification of positive cases. In particular, a detailed sexual history taking proforma ensures that the nurses asked and recorded all relevant information, including contact arrangements for results. 
While our positive results (12 chlamydia and other cases of gonorrhoea, HIV, Hepatitis B \& C and Syphilis) reflect the early implementation of the service, they clearly identify a need, particularly in detecting undiagnosed asymptomatic infections. De Burgh-Thomas and Tang (2011) have suggested that prison populations in different sites are likely to have different needs, with remand prisons likely to have a higher prevalence of blood borne viruses, due to drug use, while young offender institutions likely to have higher prevalence in chlamydia. In our pilot, cases of chlamydia were diagnosed across the sites, but, as expected blood borne viruses and syphilis were detected in the adult and remand prisoner population.

We aimed to train all prison nursing staff $(n=55)$, and achieved training with 30 in sexual health and asymptomatic testing. We then worked more intensively with a core group of 8 staff and offered them an additional 3 day training programme in sexual health promotion. However, our evaluation showed that the service is spearheaded by two staff. On the one hand, this has helped to maintain stability to the quality of the service as these nurses gain more experience and competence. However, the disadvantage is that the service could be affected by their absence or competing workload pressures. Future success will require an ongoing commitment to protecting nursing time to deliver the service and ongoing training and competency assessment of a core team of nursing staff.

\section{CONCLUSION}

This nurse led service has improved access for patients, and introduced a care pathway for more timely treatment and partner notification, improving the health and wellbeing of patients and impacting on the health of their partners and communities 
on their release. As with a similar project in community primary care (Kelly et al., 2014) this project has also shown that successful partnerships between specialist sexual services and other services can achieve well-co-ordinated services, in settings closer to hard to reach populations, whist maintaining robust clinical governance procedures addition, it has empowered nursing staff to engage in sexual health service provision and health promotion activities for their client group, which is anticipated to increase the men's self-efficacy in taking responsibility for their own and partners' health and wellbeing. By involving young men in the co design of a health promotion intervention to promote the service, we ensured it was made for and by young men in prison, increasing its accessibility. Overall, the project has also had an impact on openness to discuss issues in relation to sexual health and prison care The college for young men has been key to the success of this project because it is a European leader in promoting innovative approaches to the rehabilitation of young male offenders through education. While prisons in Northern Ireland are not currently required to provide condoms, the subject of providing condoms on release, in the first instance, is currently being discussed at policy level.

\section{RELEVANCE TO CLINICAL PRACTICE}

Prison provides an opportunity for early detection and treatment of sexually transmitted infections in an often hard to reach, priority population. This paper establishes how prison healthcare nurses, when appropriately trained and supported can provide a holistic sexual health service for asymptomatic patients. This project has also demonstrated how lead nurses, committed to breaking silo logic, can work together, creating mutually beneficial collaborations across services and directorates to develop new ways of delivering care, by improving the processes for quality and productivity. 
Tables and Figures

Table 1

Key variables in sexual history taking

Patient ID:

Age:

Documentation of sexual history

LS1

Yes

No

Condom use

Yes

No

Gender of partner

Yes

No

No of partners last $6 \mathrm{~m}$

Yes

No

HIV risk assessment

Yes

No

LPU

Yes

$\begin{array}{ll} & \text { No } \\ \text { Accepted } & \text { Yes/No }\end{array}$

Appropriate tests offered

Yes / No

Documentation how patient gets results

Yes / No

Table 2

Key performance indicators for managing chlamydia positive results

Case note audit of chlamydia positive cases in nurse led service

Working days from RESULT to TREATMENT

PN discussion documented Yes / No

All 5 tests completed Yes / No 
Figure 1

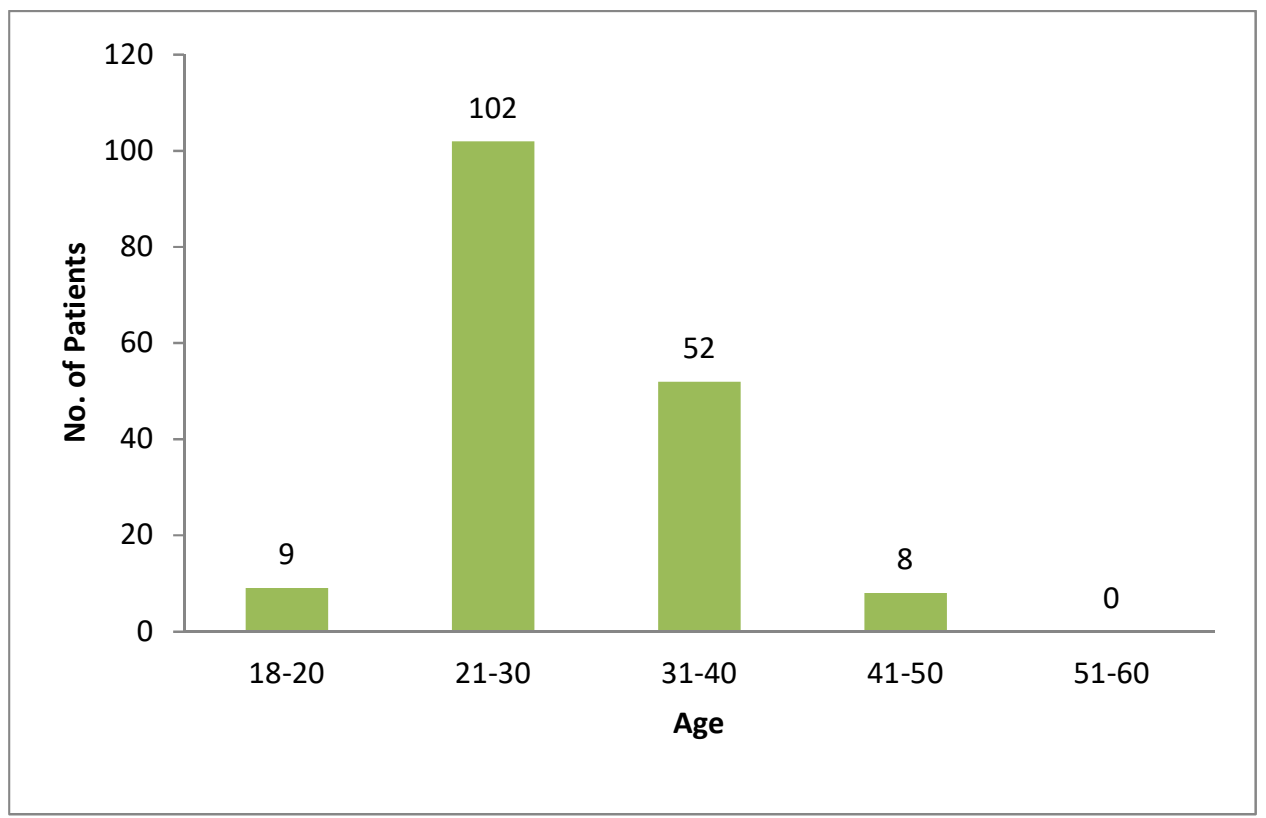

Figure 2

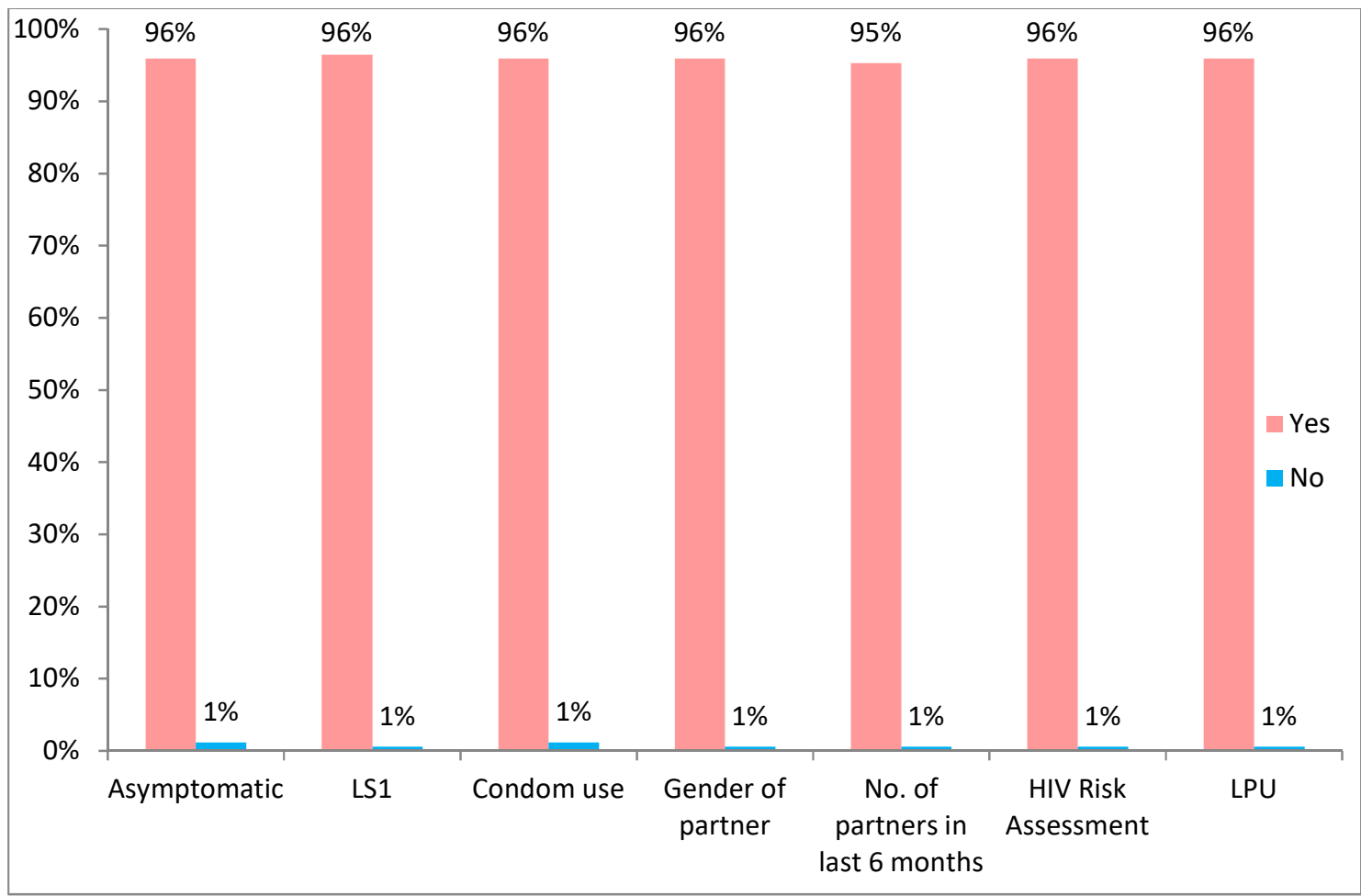




\section{REFERENCES}

Barnert, E., Perry, R., Azzi, V., Shetgiri, R., Ryan, G., Dudovitz, R., Zima, B., \& Chung, P. (2015). Incarcerated Youths' Perspectives on Protective Factors and Risk Factors for Juvenile Offending: A Qualitative Analysis. Am Jour of Public Health: Vol. 105(7), pp. 1365-1371.

British Association of Sexual Health and HIV (BASHH) (2019) Standards for the management of sexually transmitted infections (STIs).

Butler, M. (2016). What is happening to healthcare in Northern Ireland prisons? QPOL. Policy Engagement at Queen's. http://qpol.qub.ac.uk/healthcare-northernireland-prisons/. Accessed March 2017.

Condon, L., Hek, G., Harris, F., Powell, J. Kemple, T and Price S. (2006) Users' views of prison health services: a qualitative study. Journal of Advanced Nursing 58(3), $216-226$

Condon, L., Hex, G \& Harris, F. (2007). A review of prison health and its implications for primary care nursing in England and Wales: the research evidence. Journal of Clinical Nursing, pp. 1201-1209.

De Burgh-Thomas, A. Tang. On behalf of BASHH subgroup for sexual health and blood-borne viruses in prions (2011) National guidance on commissioning sexual health and blood borne services in prisons BASHH Department of Health/ HM Prison Service (2002) Developing and Modernising Primary Care in Prisons. Department of Health, London 
Department of Health (2009) Improving Health, Supporting Justice webarchive.nationalarchives.gov.uk/20130107105354/http:/.../dh 109155.pdf

Farrington , D., Gaffney, H., \& Ttofi, M. (2016). Systematic reviews of explanatory risk factors for violence, offending, \& delinquency. Aggression \& Violent Behaviour, $31-32$

Harris, F., Hek, G and Condon, L. (2006) Health needs of prisoners in England for prison healthcare of gender, age and ethnicity. Health and Social Care in the Community $15(1), 56-66$

Lohan, M., Aventin, A., Clarke, M., Curran, R., McDowell, C., Agus, A., McDaid, L., Bonell, C. and Young, H. (2018). Can teenage men be targeted to prevent teenage pregnancy? A feasibility cluster randomised controlled intervention trial in schools. Prevention Science, 1-12. https://doi.org/10.1007/s11121-018-0928-z

Kelly, C., Johnston, J. and Carey, F. (2014) Evaluation of a partnership between primary and secondary care providing accessible Level 1 sexual health service in the community. International Journal of STD \& AIDS 25 (10) 751-757.

Kupers, T. (2017). Gender and Domination in Prison. Western New England Law Review, 39.

Matthews, G., Worrell, S. and Daniels, D. (2001) Provision of sexual health services in youn offender institutions: is there gender inequality? International Journal of STD \& AIDS 12, 130-131. 
Ministry of Justice (2016). Prison Safety and Reform. Presented to Parliament by the Lord Chancellor and Secretary of State for Justice by Command of Her Majesty. Cm 9350, Her Majesty's Stationery Office. London: UK.

www.gov.uk/government/uploads/system/uploads/attachment data/file/565014/cm9350-prison-safety-and-reform- web .pdf. Accessed March 2017.

NHS England (2016) Strategic Direction for Health Services in the Justice System: 2016 -2020 https://www.england.nhs.uk/wp-content/uploads/.../hlth-justicedirections-v11.pdf

Nelson, D. and Tang, A. (2003) Sexually transmitted infections in a young offenders institution in the UK International Jornal of STD \& AIDS 14, 511-513.

Rowniak, S. \& Selix, N. (2015). Preparing Nurse Practitioners for Competence in Providing Sexual Health Care. The Journal of the Association of Nurses in AIDS Care: JANAC. DOI: 10.1016/j.jana.2015.11.010

Rumble, C., Pevalin, D. and O’Moore, E. (2015) Routine testing for blood-borne viruses in prisons: a systematic review. European Journal of Public Health 25(6) 1078-1088.

Sherrard, J. Boss, and Law, L. (2007) Experience of setting up a genitourinary medicine in-reach clinic in a male prison. International Journal of STD \& AIDS; 18 (4) 
Tang, A., Maw, R., Kell, P. (2010). A survey of sexual health services in UK prisons International Journal of STD \& AIDS (9)21: 638-641.

Templeton, M., Kelly C., \& Lohan, M. (2019) Developing a Sexual Health Promotion Intervention with Young Men in Prisons: A Rights - Based Participatory Approach JMIR Res Proc 8(4):e11829

WHO. (2014) Prisons and Health. Edited by Enggist, S., Moller, L., Galea, G. and Udesen, C. World Health Organisation.

Virgolino A., Roxo L., Alarcão V. (2017) Facilitators and Barriers in Sexual History Taking. In: IsHak W. (eds) The Textbook of Clinical Sexual Medicine. Springer. 